\title{
Urodynamics prior to surgery for urinary stress incontinence
}

\author{
K Sivanesan ${ }^{1}$ \\ Sri Lanka Journal of Obstetrics and Gynaecology 2012; 34: 120-122
}

\section{Introduction}

Urodynamics refers to wide range of invasive or non-invasive testing of the lower urinary tract. Invasive testing includes multi-channel cystometry, videocystometry and ambulatory bladder pressure monitoring.

Non-invasive testing includes mid-stream urine culture, uroflowmetry, frequency/volume chart, stress test as well as post-void residual urine volume measurement by ultrasound scan. Urodynamics attempts to qualify and quantify the lower urinary in two phases of bladder function namely bladder filling/ storage and bladder emptying. The primary goal of urodynamics (UDS) is to reproduce lower urinary tract symptoms during the study. Generally multi-channel cystometry is referred to as urodynamics.

The value of UDS prior to surgical treatment of urinary stress incontinence (USI) is a widely debated topic among urogynaecologists, yet the use of UDS is well established in the western countries and recommended by experts ${ }^{1,2}$. Countless guidelines exist regarding the management of USI, however the significance of UDS within the management varies remarkably between different units. Neither the value of UDS nor its cost effectiveness has been assessed in randomized trials.

\section{For pre-operative urodynamics}

When strict criteria applied, only $5.2 \%$ of patients who presented with urinary stress incontinence in a tertiary care unit would have pure urinary stress incontinence. Out of these, $25 \%$ of them had a diagnosis excluding urodynamic stress incontinence ${ }^{3}$. In another sizable prospective study, $78.5 \%$ of patients with pure USI had urodynamic stress incontinence, a further $7.5 \%$ had Detrusor Overactivity and $11.4 \%$ had inconclusive diagnoses ${ }^{4}$.

Further, cough provoked Detrusor Overactivity (DO) can be elicited during the cough test but could only be differentiated from USI by UDS. Mid-urethral

\footnotetext{
${ }^{1}$ The Bart's Centre for Reproductive Medicine, St. Bartholomew's Hospital, London, UK.

E-mail: sivanezan@gmail.com
}

slings are not the proposed treatment option in a cough provoked DO.

In mixed urinary incontinence, mid-urethral tapes can potentially lead to worsening of urgency and urge incontinence, which often influences the offer of surgical option in mixed incontinence.

In the UK, a survey in 2002 revealed $84.5 \%$ of the units carried out cystometry in all women with urinary incontinence, furthermore a wide variation in practice was noted ${ }^{5}$. Recently a survey between Dutch Gynaecologist and Urologists related to UDS testing in women with USI, only $37 \%$ performed standard pre-operative urodynamics. $80 \%$ of them indicated that they would operate on a patient with a positive stress test without urodynamics SUI, whereas only $21 \%$ would do this also in case the clinical stress test was negative. Many would not undertake primary surgical treatment when pre-operative $\mathrm{DO}$ is found ${ }^{6}$.

\section{Against routine pre-operative urodynamics}

Urodynamics is considered unpleasant by many patients and does carry a small risk of urinary tract infections. This is not considered a physiological way of testing the lower urinary tract. There is lack of standardization of the values and parameters. There is inconsistent reproducibility within the same patient and false negative findings. Not all the abnormalities found during UDS may have a clinically significant value.

USI could be due to intrinsic sphincter deficiency or urethral hyper-mobility. Nevertheless introduction of mid-urethral slings led to the treatment of USI in the same way irrespective of the type of USI. Though UDS may change clinical decision making, there was no evidence to suggest whether this would result in improved outcomes and recommends more substantial randomised trials (Cochrane 2012).

In $25-30 \%$ of the women with symptoms of USI, Urodynamic Stress Incontinence is not demonstrated which could be due to the artificial nature of the test ${ }^{7}$. It is widely now accepted that Urodynamic measures do not predict stress incontinence outcomes after surgery for USI. 
There are very few publications regarding USI surgery without UDS. Laurikainen $\mathrm{E}^{8}$ performed a study in which 191 patients that had tension freevaginal tape (TVT) without UDS. At a mean followup of 17 months, cure rates for USI was $97 \%$ for pure USI and $69 \%$ for mixed incontinence.

At a 10.5 year follow-up, objective and subjective cure rates were $90 \%$ and $78 \%$ respectively $(72 \%$ evaluated out of 191). Subjective cure rate was significantly lower in patients with mixed incontinence. Remarkably, even in recurrent stress incontinence patients, they observed high cure rates ${ }^{9}$.

A recent randomised trial of urodynamic testing before stress-incontinence surgery published in the New England Journal of Medicine concluded that outcomes of surgery for uncomplicated stress incontinence are similar in women who undergo office evaluation only, without urodynamics testing. OAB and voiding dysfunction were more likely to be diagnosed with pre-operative UDS but they did not lead to significant differences in outcomes. The treatment outcome was measured at 12 months postoperatively ${ }^{10}$.

\section{Current recommendations}

See chart below.

\section{Future research}

In the Netherlands, a VUSIS study is underway to assess the value of urodynamics prior to stress incontinence (BMC Women's Health 2009, 9: 22).

Conversely all the patients would undergo UDS. In the UK, INVESTIGATE-1 (INVasive Evaluation before Surgical Treatment of Incontinence Gives Added Therapeutic Effect?) is looking at the feasibility of future randomised controlled trials of the clinical utility of invasive Urodynamic testing (Murdoch et al, Trials 2011; 12: 169). Currently it is only a pilot trial, with the intention to assess the feasibility of a large multi-centre trial.

\section{Chart}

The following chart summarizes the current recommendations by various organizations on urodynamics and urinary stress incontinence.

\begin{tabular}{|l|l|}
\hline Organization & Place of UDS in USI \\
\hline NICE (UK, 2006 \& 2012) & $\begin{array}{l}\text { Does not need UDS if pure USI (CG40) } \\
\text { Does not need if conservative management of urinary } \\
\text { incontinence } \\
\text { Does not need routine UDS in neurological patients } \\
\text { if risk of renal damage is low (e.g. multiple } \\
\text { sclerosis) (CG148) }\end{array}$ \\
\hline $\begin{array}{l}\text { Society of Obstetricians and } \\
\text { Gynecologists Canada }{ }^{12,13}\end{array}$ & Does not recommend if diagnosis is clear \\
\hline $\begin{array}{l}\text { American College of Obstetricians and } \\
\text { Gynecologists (ACOG, 2005) }\end{array}$ & Does not recommend if diagnosis is clear \\
\hline $\begin{array}{l}\text { French College of Obstetricians } \\
\text { and Gynaecologists }\end{array}$ & $\begin{array}{l}\text { Does not require if pure USI and a comprehensive } \\
\text { assessment carried out }\end{array}$ \\
\hline $\begin{array}{l}\text { International Continence Society (2005) } \\
\text { there are no complicating factors involved }\end{array}$ \\
\hline $\begin{array}{l}\text { Dutch Urological Association, Dutch Society } \\
\text { of Obstetricians and Gynaecologists, } \\
\text { European Association of Urology }\end{array}$ & $\begin{array}{l}\text { Recommend UDS prior to any surgical } \\
\text { measures for USI }\end{array}$ \\
\hline
\end{tabular}




\section{Conclusion}

Focused history taking, QoL questionnaires, voiding diary, pelvic examination including cough test, demonstration of mobility of the urethrovesical junction (by ultrasound scan), post-void residual urine volume measurement, urine analysis/urine culture and uroflowmetry should be part of basic evaluation of a patient with USI prior to primary surgery ${ }^{12,13}$.

It is widely accepted that recurrent urinary incontinence following surgery requires more detailed evaluation including UDS. Performing UDS prior to pelvic organ prolapse is controversial at present.

The outcome of the future randomized trials could potentially help the clinicians in deciding the role of UDS in the management of USI.

\section{References}

1. Fowler G, Richmond D. Urodynamics: a mandatory preoperative investigation? The Obstetrician and Gynaecologist 2006; 8(2): 86-90.

2. MacLean AB, Cardoza L. Recommendations arising from the 42nd study Group in incontinence in women. Edited by: MacLean AB, Cardoza L. London: RCOG Press; 2002: 433-41.

3. Agur W, Housami F, Drake M, Abrams P. Could the National Institute for Health and Clinical Excellence Guidelines on Urodynamics on Urinary Incontinence put some women at risk of bad outcome from stress incontinence surgery? BJU Int 2009; 103(5): 635-9.

4. Digesu GA, Hendricken C, Fernando R, Khullar V. Do women with pure stress urinary incontinence need urodynamics? 2009; 74(2): 278-81.

5. Adekanmi OA, Edwards GJ, Barrington JW. The variation in urodynamic practice in the United Kingdom. J Obstet Gynaecol 2002; 22(1): 48-50.

6. Van Leijsen SAL, Kluivers KB, Mol BWJ, et al. The value of preoperative urodynamics according to gynecologists and urologists with special interest in stress urinary incontinence. Int Urogynaecol J 2012; 23: 423-8.

7. Van Waalwijk van Doorn ES, Remmers A, Janknegt RA. Conventional and extramural ambulatory urodynamic testing of the lower urinary tract in female volunteers. J Urol 1992; 147(5): 1319-25.

8. Laurikainen E, Kiilholma P. The tension-free vaginal tape procedure for female urinary incontinence without preoperative urodynamic evaluation. J Am Coll Surg 2003; 196(4): 579-83.

9. Heinonen P, Ala-Nissila S, Kiilholma P, Laurikainen E. Tension-free vaginal tape procedure without preoperative urodynamic examination: long-term outcome. Int J Urol 2012 Jun doi: 10.1111/j.1442-2042.2042.2012.03078.x.

10. Nager $\mathrm{CW}$ et al. A randomised trial of urodynamic testing before stress incontinence. N Engl J Med 2012; 336: 1987-97.

11. Fritel X, Fauconnier A, Bader G, et al. Diagnosis and management of adult female stress urinary incontinence: guidelines for clinical practice from the French College of Gynaecologists and Obstetricians. Eur J Obstet Gynaecol Reprod Biol 2010; 151(1): 14-9.

12. Farrell SA. The evaluation of stress incontinence prior to primary surgery. J Obstet Gynaecol Can 2003; 25(4): 313-8.

13. Amir B, FarrellSA. SOGC Committee opinion on urodynamic testing. J Obstet Gynaecol Can 2008; 30(8): 717-21. 